\title{
Article \\ Optimization of Energy Recovery from Hazardous Waste in a Waste Incineration Plant with the Use of an Application
}

\author{
Agata Wajda ${ }^{1}$ (D), Rafał Brociek ${ }^{2}$ (D) and Mariusz Pleszczyński ${ }^{2, *(D)}$ \\ 1 Department of Technologies and Installations for Waste Management, Faculty of Energy and Environmental \\ Engineering, Silesian University of Technology, 44-100 Gliwice, Poland; agata.wajda@polsl.pl \\ 2 Department of Mathematics Applications and Methods for Artificial Intelligence, Faculty of Applied \\ Mathematics, Silesian University of Technology, 44-100 Gliwice, Poland; rafal.brociek@polsl.pl \\ * Correspondence: mariusz.pleszczynski@polsl.pl; Tel.: +48-32-237-17-88
}

check for updates

Citation: Wajda, A.; Brociek, R.; Pleszczyński, M. Optimization of Energy Recovery from Hazardous Waste in a Waste Incineration Plant with the Use of an Application. Processes 2022, 10, 462. https:/ / doi.org/10.3390/pr10030462

Academic Editor: Alok Kumar Patel

Received: 31 December 2021

Accepted: 18 February 2022

Published: 24 February 2022

Publisher's Note: MDPI stays neutral with regard to jurisdictional claims in published maps and institutional affiliations.

Copyright: (c) 2022 by the authors. Licensee MDPI, Basel, Switzerland. This article is an open access article distributed under the terms and conditions of the Creative Commons Attribution (CC BY) license (https:// creativecommons.org/licenses/by/ $4.0 /)$.

\begin{abstract}
Recovering energy from waste is a positive element in the operation of a waste incineration plant. Hazardous waste is a very diverse group, including in terms of its fuel properties. Carrying out the thermal process in this case is associated with the difficulty in maintaining stable conditions. This may translate into the efficiency of energy recovery from waste. The article presents a tool supporting the work of hazardous waste incineration plant operators, the aim of which is to select waste for a batch of input material in a manner that ensures process stability and efficient energy recovery. The tool is an application in which the bee algorithm is implemented. It selects the optimal solution to the problem, in accordance with the assumed parameters. The application tests in laboratory conditions were satisfactory and indicated compliance with the assumptions and stability of the solution.
\end{abstract}

Keywords: optimization algorithm; hazardous waste; energy recovery; energy from waste

\section{Introduction}

Thermal waste treatment occupies a specific place in the waste hierarchy [1]. As part of this issue, it is worth paying attention to the differentiation of related regulations depending on the type of waste. According to the idea of circular economy, waste should be primarily prepared for reuse, and if this is not possible, recycled. This mainly applies to municipal waste, for which EU authorities have set appropriate recycling rates and landfill limits [2-5]. As part of the common waste policy, reference was also made to an element of the waste management system, which is the incineration plant, the role of which is defined as a waste neutralizing device, the recovery of which is practically impossible. Storage is prohibited in accordance with [3]. The incineration of municipal waste limits the disposal of waste and allows the recovery of the energy contained in them.

The situation related to the thermal processing of industrial waste, mainly hazardous waste, is different. This type of waste is not subject to the management levels mentioned above. For these wastes, there is often no alternative management method other than thermal. In addition, there is an aspect of the neutralization of harmful substances contained in waste. Considering the increasing amount of hazardous waste $[2,6,7]$, the development of this type of installation can be assumed. In particular, the COVID-19 pandemic, which is associated with a significant increase in medical waste requiring thermal neutralization, has indicated the importance of such devices [6,7]. The activity of hazardous waste incineration plants does not contradict the idea of circular economy and even complements the system $[6,8]$. Based on the authors' experience, it is also worth emphasizing that hazardous waste incinerators recover large amounts of energy contained in waste, which they allocate to meet their own needs and often also the needs of neighboring industrial plants. This is one of the positive elements of the activity of this type of facility.

Hazardous wastes are incinerated in a rotary kiln. This process can take place in a cement plant, where some types of industrial waste are a fuel substitute, and in dedi- 
cated hazardous waste incineration plants, where various types of industrial waste are neutralized, but also, for example, medical waste [9-11]. Cement plants and hazardous waste incineration plants differ in several aspects, among which the level of diversification of waste converted and the related effects are important for this study. While cement plants accept fuel from waste with specific fuel and physico-chemical parameters, hazardous waste incinerators accept very diverse types of waste with different properties and streams [11,12]. This results in the necessity to select different types of waste for the portion of the input material. Proper selection of the feed mixture, ensuring effective operation of the incinerator, requires knowledge, experience and time from the operator of the rotary kiln. This is a very important issue for the operation of hazardous waste incineration plants. The huge diversification of waste and its inappropriate selection for loading may cause operational problems, breakdowns, and instability of the thermal process, limiting energy recovery from waste, as well as temporarily exceeding the permissible emission standards of harmful gases into the atmosphere [11-13].

Hence, it is important to try to support the decision-making process in a hazardous waste incineration plant in the form of an automation tool. The literature review of the subject did not indicate similar considerations. Usually, researchers focus on possible causes of operational problems of the rotary kiln, examining fragments of its internal surface-brick lining-after the use phase [14-16]. In [14], the authors determined that the damage to the furnace lining is primarily caused by alkaline corrosion. Similar considerations were also presented in $[15,16]$, where the authors also proved the negative effect of alkali salts on the lining of the rotary kiln. However, these are the studies that are part of the issue of the protection of the rotary kiln against the adverse effects of aggressive hazardous waste. In this work, attention was paid to the aspect of stable energy recovery from waste in an incineration plant using a dedicated, supporting tool. A similar problem was not encountered during the literature review. Ref. [13], which contained the general principles of conducting the process in a waste incineration plant, turned out to be the closest to this issue. The reason for the insignificant number of references may be the practical approach to the problem. Most of the information, procedures and suggestions necessary to develop the concept of the solution were obtained from the operators of thermal treatment plants for hazardous waste.

The paper presents an application for the selection of hazardous waste for a batch of input material in a hazardous waste incineration plant. The selection criteria are the fuel properties of individual wastes, which are essential to ensure a stable charge in terms of effective energy recovery. Efficient recovery means recovering energy from waste at a certain level and reducing potential problems with increased emissions. In order to achieve this, the waste in the mixture must meet certain values of the given parameters. The developed approach is based on practical experience from a real object. Considering the importance of the selection of the input material mixture, it can be stated that a tool supporting this process is a tool that optimizes the operation of a waste incineration plant. This solution is a continuation of the previous research contained in [7], in which the appropriate selection was related to other criteria and was supposed to limit operational problems. An additional research aspect of this study is the possibility of comparing the results with those obtained for a set of other criteria. As the solution uses a different type of heuristic algorithm, the obtained results can be related to the results presented in [7].

The tool presented in the paper is an application of the selection of components and their masses for the batch of input material in a hazardous waste incineration plant. The application was written in NET technology in the C\# programming language based on the bee algorithm. The aim of this tool is to automatically select the components of the waste mixture that will constitute the portion of the input material. The selection criteria are given properties of waste and their values, which will allow to obtain a portion of the material with stable fuel parameters. This will translate into an effective incineration and energy recovery process, as well as the minimization of problems related to gas emissions from the process. 


\section{Materials and Methods}

\subsection{Aim of the Study}

The selection of different types of waste for a batch of input material is the core of the work of operators of hazardous waste incineration plants. With regard to stable energy recovery from waste, which is currently assessed very positively, it requires the continuous loading of portions of material with stable fuel parameters. In the case of diversified waste and its streams, this is a demanding task. It requires a lot of time, experience and concentration. Therefore, it seems justified to create tools supporting these activities.

The wrong selection of waste for loading can lead to various negative consequences. For example, by using input materials with different fuel properties, such as the calorific value, it is possible to reduce the energy potential of the loading and the need to use conventional fuels supporting the process. A lot of hazardous waste is characterized by good or very good fuel properties. Nevertheless, there are also those that are poor fuel, or even ballast - a mineral material. Then, if possible, it is worth combining waste with different properties in a portion of the input material. The aim here is to achieve the optimal fuel characteristics of the batch material that ensure a stable thermal process as well as the saving of conventional fuel, which is most often natural gas. One can imagine a situation in which a waste incineration plant has, for example, medical waste with good fuel properties, waste from the plastics industry with a very high calorific value, and metal or glass packaging for chemicals, which can be practically considered ballast materials during combustion. The proper combination of these wastes during loading allows to achieve a stable process with energy recovery. However, when practically zero caloric waste is fed to the kiln without additives to support the thermal process, additional fuel must be supplied, increasing costs. In such a case, it is worth supporting the process of thermal neutralization of such problematic waste with the energy contained in other waste, which will enable the autothermal incineration process. On the other hand, loading waste with a high calorific value, for example, $35 \mathrm{MJ} / \mathrm{kg}$, can lead to an overload of the installation. Another aspect worth considering is the limitation of possible emissions of exhaust gases. An input material with a high sulfur content may temporarily exceed the emission standards for sulfur oxides. Therefore, it is worth supplementing the loading with a high content of this element, or other ones influencing emissions, with waste with a negligible share.

\subsection{Assumptions}

The developed tool allows to generate the composition of the mixture, which is a portion of the input material for the rotary kiln in a hazardous waste incineration plant. The list of waste from which this selection can be made, according to the authors, is based on the waste of incineration plants. The selection criteria are selected properties of the waste. The study selected the most important parameters, proving the fuel properties of the waste. They are most often used to characterize waste in terms of its energy potential, both in theoretical and practical considerations. They are also determined in the laboratory of incineration plants precisely in order to classify a given waste. The selected parameters are the calorific value and the content of ash, moisture, chlorine and sulfur.

Based on the experience gained, inter alia, during study visits to waste incineration plants and laboratory work related to the incineration of waste samples, each parameter was assigned a range of values. Then, for each range, the optimal value of the given parameter was selected, which is here the reference value. The list of all parameters with their value ranges and optimal values is presented in Table 1. 
Table 1. Assumptions of the application parameters and their values.

\begin{tabular}{ccccc}
\hline Parameter & Symbol & Unit & Value Range & Reference Value \\
\hline Calorific value of waste & P1 & MJ $/ \mathrm{kg}$ & $14-22$ & 18 \\
Content of ash & P2 & $\%$ mass & $<20$ & 10 \\
Content of moisture & P3 & $\%$ mass & $<20$ & 10 \\
Content of chlorine & P4 & $\%$ mass & $<10$ & 1 \\
Content of sulfur & P5 & $\%$ mass & $<5$ & 0.5 \\
\hline
\end{tabular}

The reference values for the first three parameters—calorific value, ash and moisture content-were established as an average value. In the case of ranges-maximum values for chlorine and sulfur content-the optimal value for the waste mixture was defined as $10 \%$ of the given maximum value. The introduction of a reference value also has another benefit, thanks to this model being more resistant to certain deviations in the operation of the algorithm. There is a relatively large margin of error, while allowing output values to be obtained within the specified parameter ranges. It is also assumed that the initial values of the individual batch parameters are weighted averages of its components. The weight in this case is the mass of the component in the mixture.

\subsection{The Algorithm}

In the first step, an objective function was created, which is defined as follows:

$$
f\left(s_{1}, s_{2}, \ldots, s_{5}\right)=\sum_{i=1}^{5}\left(\bar{p}_{i}-p_{w i}\right) x^{2}
$$

where $s_{1}, s_{2}, \ldots, s_{n}$-masses (weights) of individual components,

$n$-number of ingredients, and

$\bar{p}_{i}=\frac{m_{j} \cdot c_{i}\left(w_{j}\right)}{\sum_{j} m_{j}}$-weighted average of the parameter with index $i$, where $m_{j}$-mass of the $j$-th waste, $c_{i}\left(w_{j}\right)$-value of the $i$-th parameter in the $j$-th waste, $\sum_{j} m_{j}$-adding up after all the waste included in the mixture, and $p_{w i}$-reference value of the parameter.

The objective function is a function of $\mathrm{n}$ variables, where $\mathrm{n}$ is the number of components that can be in the mixture. Then it is minimized in relation to the weight of a given component. The objective function describes how a meshing relates to certain parameters. The relationship is as follows: the smaller the value of the function, the more the mixture will have the values of individual parameters close to the reference values.

The objective function was minimized by using one of the artificial intelligence algorithms - the bee algorithm. The selected algorithm is classified as being easy to implement. The operation of the algorithm can be simplified as follows: the algorithm receives a set of waste from which a mixture is formed and then selects the masses of individual selected waste so that their mixture is characterized by standard values.

The implementation of heuristic algorithms is a common way to solve optimization problems $[17,18]$. One of the heuristic algorithms - the bee algorithm —was chosen to solve the problem posed in the paper. It is inspired by the behavior of animals in nature, in this case, bees. Bees searching for a food source can be divided into two groups: working bees, which are currently searching for a food source, and non-classified bees, which are looking for new sources of food. Non-classified bees are divided into scouts and viewers. Scouts, after leaving their food source, look for another one at random; however, based on the information provided, viewers look for visited sources. Bees exchange information about a food source by dancing. Non-classified bees belonging to the group of viewers, by observing the dance, can choose the most appropriate food source for themselves. Once located by the bee of the food source, it remembers its position and passes immediately for its exploration. After collecting enough nectar, it returns to the hive, and unloads the harvested food [19-21].

Based on the above, the following is assumed: 
- The positions of the food sources correspond to the possible solutions of the optimized topics;

- The amount of nectar in the source corresponds to the quality of the solution,

- The number of working bees is equal to the number of viewers; this number is marked by SN.

The bee algorithm can be presented in the following steps:

1. Starting the algorithm by assigning the input data:

- $\quad \mathrm{SN}$-number of nectar sources = number of employed bees = number of viewers;

- $\mathrm{MCN}-$ number of iterations;

- $\mathrm{F}(x)$-objective function, where $x=\left(x_{1}, x_{2}, \ldots, x_{n}\right)$;

- $\quad$ vectors $\mathrm{a}, \mathrm{b}$, with $n$ coordinates, limiting the area of searching for a solution, from the bottom and the top, respectively.

2. Randomly generate the initial population $\mathrm{P}$ (vectors $x^{i}=\left(x_{1}^{i}, x_{2}^{i} \ldots, x_{n}^{i}\right), i=1,2$, ..., SN).

3. Calculate the value of the objective function $\mathrm{F}$ for the elements of the initial population $\mathrm{P}\left(\mathrm{F}\left(x^{i}\right) i=1,2, \ldots, S N\right)$ and keep the best solution as $x^{b e s t}$.

4. Modify the position of all food sources according to the formula

$$
v_{j}^{i}=x_{j}^{i}+\Phi_{i j}\left(x_{j}^{i}-x_{j}^{k}\right)
$$

where:

$$
j \in\{1,2, \ldots, n\},
$$

$$
\begin{gathered}
k \in\{1,2, \ldots, S N\} \wedge k \neq i \text {-randomly selected index, } \\
\Phi_{i j} \in[-1,1] \text {-a randomly generated number. }
\end{gathered}
$$

5. Compare sources $x^{i}$ with $v^{i}$. If $\mathrm{F}\left(v^{i}\right) \leq \mathrm{F}\left(x^{i}\right)$, then $x^{i}=v^{i}$; otherwise, source $x^{i}$ remains unchanged.

6. Repeat points 4 and 5 of the algorithm $S N \cdot n$ times.

7. To all sources $x^{i}$, we assign probabilities according to formula

$$
p_{i}=\frac{f i t\left(x^{i}\right)}{\sum_{j=1}^{S N} f i t\left(x^{j}\right)} \quad i=1,2, \ldots, S N,
$$

8. Each of the bees selects one source according to the probability $p_{i}$ (selected sources can be repeated) and starts modifying it accordingly with the formula in point 4 and compares the sources as in step 5.

9. If, after executing step 8 of the algorithm, one of the sources has not changed its position, then they are lowered and replaced with a new defined source formula:

$$
x_{j}^{i}=x_{\text {min }}^{i}+\omega_{i j}\left(x_{\text {max }}^{i}-x_{\text {min }}^{i}\right), \quad i=1,2, \ldots, S N,
$$

where $\omega_{i j} \in[0,1]$ is a pseudo-random number.

10. From the existing sources, we choose the best and mark it with $x^{\text {best }}$. If this is the best source we have received so far, we keep it. Otherwise, we ignore it and remember the previous best source.

11. We repeat the steps of the algorithm 4 to $10 \mathrm{MCN}$ times.

For fixed values of $\mathrm{SN}$ and MCN parameters, the number of the function call target for running the algorithm is $S N+\left(S N^{2} \cdot n+S N\right) \cdot \mathrm{MCN}$, where $n$ is the dimension of the task. 


\section{Results}

The assumption of the developed application for the selection of components of the waste mixture is to use it in real facilities-incineration plants. In order to be able to consider testing an actual installation, the application must be tested and properly prepared. The first aspect is to fulfill the main purpose of the tool, namely the selection of waste and their masses for the mixture constituting the portions of the input material in accordance with the adopted assumptions. These assumptions relate to obtaining a mixture with stable parameters, which can be defined as the basic fuel properties. The selection should ensure the optimal composition of the mixture, which will translate into effective energy recovery, saving conventional fuels and minimizing problems related to emissions from the thermal process.

Nevertheless, important features of the proposed solution, in accordance with the assumptions for use, are ease of use, repeatability of solutions, flexibility and the possibility of direct use in the work of a waste incineration plant operator. The further part of the work presents the simulation results, which are also an element of testing the developed model.

As part of the proposed solution, it is also possible to distinguish detailed functions of the application user, which include the following:

- Connecting the application with the database of the waste incineration plant.

- Creating a mixture-portions of the input material — with the given parameters.

- Updating the amount of waste after each selection.

- $\quad$ Reporting and archiving.

\subsection{Connecting the Application with the Database of the Waste Incineration Plant}

The application dedicated to hazardous waste incineration plants should be compatible with the database of incinerators. In basic terms, it is the ability to load data about the waste received by the incineration plant into the application, which allows the operator to upload data about waste from the incinerator's laboratory with one button. Excel file was selected as the file format, as it is commonly used. In addition to this function, the user of the application also has other possibilities, which are presented in the following points. In addition, efforts were made to develop the graphic design of the application in a transparent and easy-to-use manner. There is no upper or lower limit to the number of wastes that can be loaded, although we note that a minimum of two must be loaded for a mixture to form.

\subsection{Creating a Waste Mixture with the Given Parameters}

This function is the basic element on which the idea of implementing such a solution was built. Due to the implementation of the selected algorithm, satisfactory results were obtained. The performed tests indicate the repeatability of the generated results. In all the tests, the values of the parameters of the obtained mixture were very close to the set reference values. Thus, a high compliance with the assumed guidelines can be indicated. Examples of application tests showing the achievement of the basic aim of the application are shown in Figures 1-3. 


Waste mixture selection tool
\begin{tabular}{|c|c|c|c|c|c|c|c|}
\hline Name & Weight $[\mathrm{kg}]$ & Calorific value [MJ/kg] & Ash [\%] & Moisture [\%] Cl [\%] & $\mathrm{S}[\%]$ \\
\hline Waste 10 & 270 & 18 & 18 & 18 & 1.5 & 0.5 & \\
\hline Waste 11 & 780 & 10 & 6.5 & 9 & 3.5 & 2 & \\
\hline Waste 12 & 1430 & 13 & 24.5 & 22 & 0 & 0 & \\
\hline Waste 13 & 90 & 23 & 21 & 4.5 & 2.5 & 0.5 & \\
\hline Waste 14 & 160 & 9.5 & 9 & 13.5 & 1.2 & 0.5 & \\
\hline Waste 15 & 1150 & 14 & 5 & 4.5 & 0 & 0 & \\
\hline Waste 16 & 615 & 13 & 16 & 2 & 0.5 & 0 & \\
\hline Waste 17 & 238 & 8 & 5 & 11 & 3.5 & 1.25 & \\
\hline Waste 18 & 505 & 28 & 11 & 15 & 0 & 0 & \\
\hline Waste 19 & 90 & 14 & 27 & 65 & 18 & 4.2 & \\
\hline Waste 20 & 850 & 9 & 4 & 45 & 14.5 & 2.1 & \\
\hline .. & $\ldots$ & $\ldots$ & $\ldots$ & & & \\
\hline
\end{tabular}

Maximum batch mass: $200 \mathrm{~kg}$

Figure 1. Functionality of the application.

W. Waste mixture selection tool

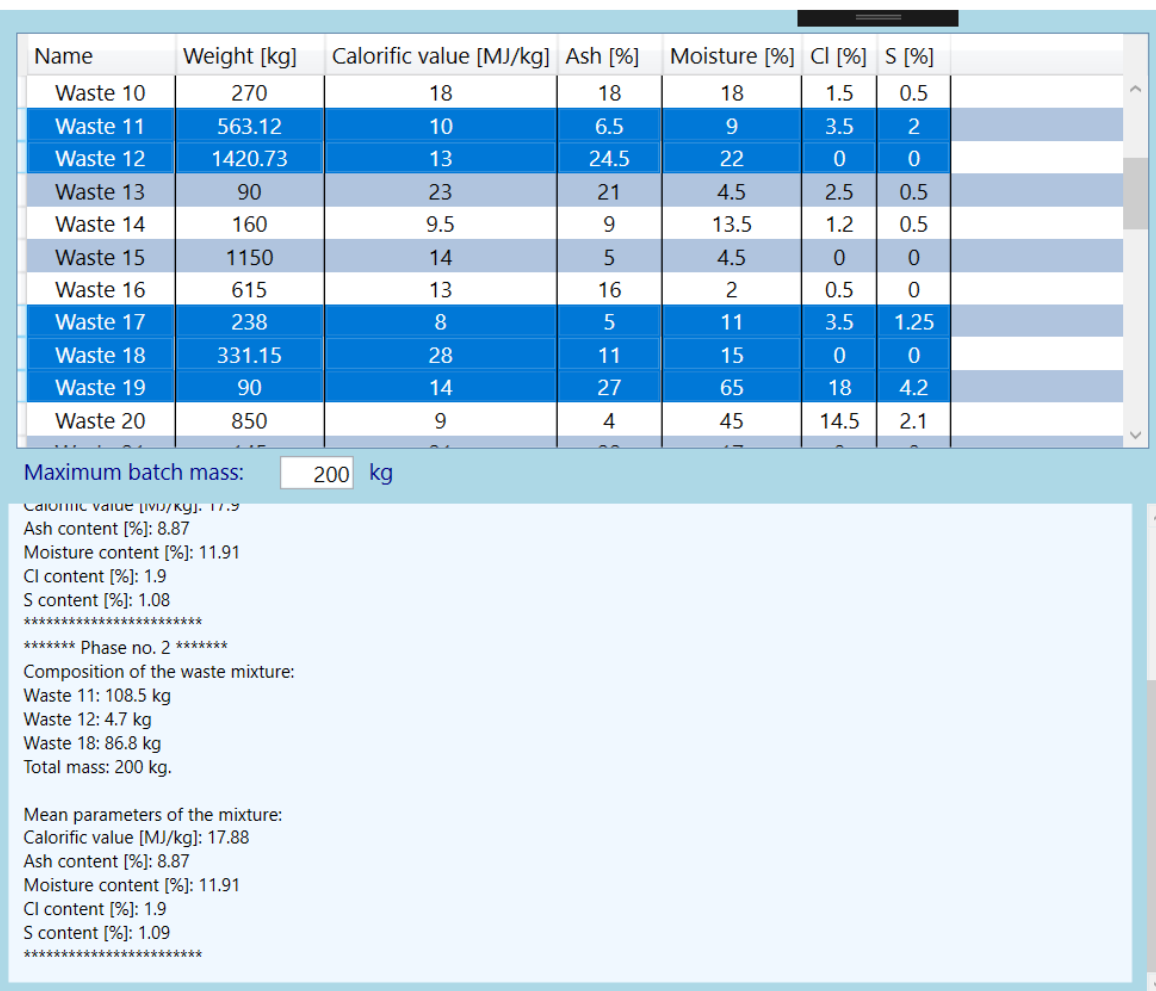

Load data

\section{Start selecting mixture}

Save list of waste

\section{Save results}

Waste mixture range values for the parameters: $14<$ calorific value $[\mathrm{MJ} / \mathrm{kg}]<22$

$0<$ ash content [\%] $<20$

$0<$ moisture content [\%] $<20$

$0<\mathrm{Cl}[\%]<10$

$0<\mathrm{S}[\%]<5$

Figure 2. Creating a mixture of the waste portion.

Waste mixture range values for the parameters: $14<$ calorific value $[\mathrm{MJ} / \mathrm{kg}]<22$

$0<$ ash content $[\%]<20$

$0<$ moisture content [\%] $<20$

$0<\mathrm{Cl}[\%]<10$

$0<\mathrm{S}[\%]<5$

\section{Load data}

Start selecting mixture

Save list of waste

\section{Save results}




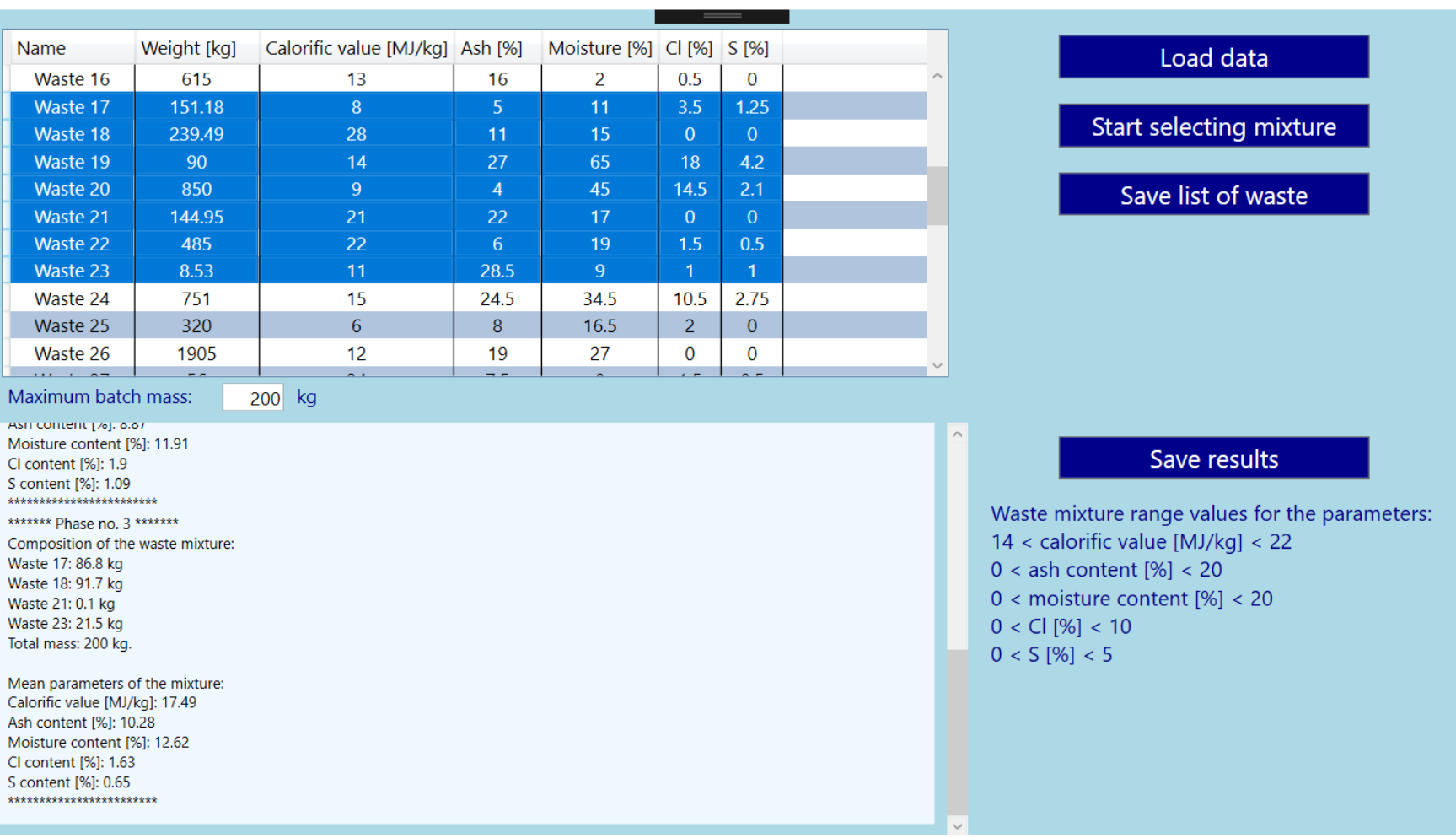

Figure 3. Results of creating batch portion after changing maximum batch mass.

\subsection{Updating the Amount of Waste after Each Selection}

Working in a waste incineration plant is a dynamic and continuous process. Loading, excluding renovations, takes place without breaks with high frequency. Hence, it is important to update each change indicated by the application. The answer to this is the function for the application user, which consists in updating waste masses after their use into a waste mixture constituting a portion of the input material. Each mass loss is demonstrated, which increases the comfort of the incinerator operator. Tests verifying this function showed that with each choice of given materials, their masses decreased. Here, also stable and correct solutions were found.

An interesting solution is also the possibility of individual selection of waste from which a given mixture is made. This is not necessary but may be needed in a situation where an operator has several types of waste that should be thermally converted at a given point in time. This may be the result of the high nuisance of some wastes, which cannot be stored and should be utilized as soon as possible. Often, such wastes will require the selection of other wastes with opposite parameters; hence, the solution enabling the selection of several is appropriate here.

\subsection{Reporting and Archiving}

An important function of the application is the ability to save the generated data for individual waste mixtures and create a report on their basis. This is an important solution for the operator of a waste incineration plant. It facilitates the management of the warehouse with waste awaiting incineration and loading and enables the assessment of previously used mixtures in terms of energy recovery or emissions. The user of the application can obtain a report containing the summary of information on the batch of input material at specified time intervals. Another possibility of using this functionality, knowing the frequency of loading in a given facility, is that it is possible to generate a loading schedule for one day or week. Due to the changing situation in the waste incineration plant, 
it seems that longer predictions are unlikely to apply here but can also be demonstrated. Figure 3 shows the formation of an input batch with a changed batch material weight.

\section{Conclusions}

The developed application of the selection of components for portions of input material in terms of energy recovery from waste in a hazardous waste incineration plant, as a result of the tests carried out, gave satisfactory results. All the generated mixtures were in line with the assumptions. The created tool is simplified and requires further testing and development. It seems, however, that the course of action is good, and the functionality meets the basic requirements, referring to the nature of the work of the operators of thermal treatment installations for hazardous waste.

An open question is the method of determining the mass composition of the mixture. It is done on the basis of a weighted average. One may wonder about the possible interaction of individual components of the mixture with each other in conditions of increased temperature. The created application does not assume that other specific data should be taken into account when selecting components and their masses. Nevertheless, it is difficult to predict and investigate such a possible impact. Testing on a real object seems to be the only way. The proposed solution is an attempt to facilitate the work of incineration plant operators in a way that allows stabilization and even an increase in the efficiency of energy recovery from waste.

Author Contributions: Conceptualization, A.W.; methodology, A.W.; software, A.W., R.B. and M.P.; validation, A.W., R.B. and M.P.; formal analysis, A.W., R.B. and M.P.; investigation, A.W.; resources, A.W.; data curation, A.W.; writing — original draft preparation, A.W., R.B. and M.P.; writing-review and editing, A.W., R.B. and M.P.; visualization, A.W., R.B. and M.P.; supervision, A.W. All authors have read and agreed to the published version of the manuscript.

Funding: This research received no external funding.

Data Availability Statement: Not applicable.

Conflicts of Interest: The authors declare no conflict of interest.

\section{References}

1. Poranek, N.; Łaźniewska-Piekarczyk, B.; Czajkowski, A.; Pikoń, K. Circular Economy for Municipal Solid Waste Incineration Bottom Ash (MSWIBA) Management in Mortars with CSA and CEM I, MSWIBA Glassy Phase, and DTG. Energies 2022, 15, 135. [CrossRef]

2. Wajda, A.; Jaworski, T. Research on the incineration processes of the solid waste in a rotary kiln. In Proceedings of the 19th International Multidisciplinary Scientific GeoConference, Albena, Bulgaria, 28 June-7 July 2019; Energy and Clean Technologies; STEF92 Technology: Sofia, Bulgaria, 2019; Volume 19, pp. 367-374.

3. Circular Economy Action Plan. Available online: http://ec.europa.eu/environment/circular-economy/index_en.htm (accessed on 20 December 2021).

4. Ellen Macarthur Foundation. Circular Economy. Available online: https://ellenmacarthurfoundation.org/topics/circulareconomy-introduction/ overview (accessed on 21 December 2021).

5. Bogacka, M.; Poranek, N.; Łaźniewska-Piekarczyk, B.; Pikon, K. Removal of Pollutants from Secondary Waste from an Incineration Plant: The Review of Methods. Energies 2020, 13, 23. [CrossRef]

6. Pikon, K.; Poranek, N.; Czajkowski, A.; Lazniewska-Piekarczyk, B. Poland's Proposal for a Safe Solution of Waste Treatment during the COVID-19 Pandemic and Circular Economy Connection. Appl. Sci. 2021, 11, 9. [CrossRef]

7. Wajda, A.; Jaworski, T. Optimization and Security of Hazardous Waste Incineration Plants with the Use of a Heuristic Algorithm. Sensors 2021, 21, 7247. [CrossRef] [PubMed]

8. Ecogenerator. Available online: http://www.ecogenerator.eu/ecogenerator/spalarnie-w-europie (accessed on 22 December 2021).

9. Wang, J.; Mao, E.; Ye, Y.; Zhou, Y.; Hu, J.; Xu, R. Corrosion of disposing urban domestic wastes on refractories for cement rotary kiln. China Refract. 2016, 25, 2.

10. Granados, D.A.; Chejne, F.; Mejia, J.M. Oxy-fuel combustion as an alternative for increasing lime production in rotary kilns. Appl. Energy 2015, 158, 107-117. [CrossRef]

11. Bujak, J. Determination of the optimal area of waste incineration in a rotary kiln using a simulation model. Waste Manag. 2015, 42, 148-158. [CrossRef] [PubMed] 
12. Slovikovskii, V.V.; Gulyaeva, A.V. Efficient corrosion/erosion-resistant lining for rotary kilns. Refract. Ind. Ceram. 2021, 61, 6. [CrossRef]

13. Bani-Hani, E.; Hammad, M.; Matar, A.; Sedaghat, A.; Khanafer, A. Numerical analysis of the incineration of polychlorinated biphenyl wastes in rotary kilns, Journal of Environmental. Chem. Eng. 2016, 4, 624-632.

14. Gajendra, K.; Shabina, K. Computational fluid dynamics of sponge iron rotary kiln. Case Stud. Therm. Eng. 2017, 9, 14-27.

15. Njeng, A.; Vitu, S.; Clausse, M.; Dirion, J.-L.; Debacq, M. Wall-to-solid heat transfer coefficient in flighred rotary kilns: Experimental determination and modelling. Exper. Therm. Fluid Sci. 2018, 91, 197-213. [CrossRef]

16. Villalba Weinberg, A.; Varona, C.; Chaucherie, X.; Goeuriot, D.; Poirier, J. Extending refractory lifetime in rotary kilns for hazardous waste incineration. Ceram. Int. 2016, 42, 17626-17634. [CrossRef]

17. Brusca, S.; Capizzi, G.; Lo Sciuto, G.; Susi, G. A new design methodology to predict wind farm energy production by means of a spiking neural network based system. Int. J. Numer. Model. Electron. Netw. Devices Fields 2019, 32, 4. [CrossRef]

18. Pleszczyński, M. Implementation of the computer tomography parallel algorithms with the incomplete set of data. PeerJ Comput. Sci. 2021, 7, e339. [CrossRef] [PubMed]

19. Brociek, R.; Słota, D. Application of intelligent algorithm to solve the fractional heat conduction inverse problem. In International Conference on Information and Software Technologies; Springer: Cham, Switzerland, 2015; Volume 538, pp. 356-365.

20. Brociek, R.; Słota, D. A method for solving the time fractional heat conduction inverse problem based on ant colony optimization and artificial bee colony algorithms. In Proceedings of the 23rd International Conference, ICIST 2017, Druskininkai, Lithuania, 12-14 October 2017; Springer: Cham, Switzerland, 2017; pp. 351-361.

21. Połap, D.; Srivastava, G. Neural image reconstruction using a heuristic validation mechanism. Neural Comput. Appl. 2020, 36, 10787-10797. [CrossRef] 